\title{
Herold Toussaint, Sociologie d'un Jésuite haïtien. Karl Lévêque, éducateur politique
}

Port-au-Prince, Éditions Presses Nationales d'Haïti, 2014, 291 p.

\section{Michael Löwy}

\section{(2) OpenEdition}

\section{Journals}

Édition électronique

URL : http://journals.openedition.org/assr/27476

DOI : $10.4000 /$ assr. 27476

ISSN : $1777-5825$

Éditeur

Éditions de l'EHESS

Édition imprimée

Date de publication : 1 octobre 2015

Pagination : 382

ISBN : 978-2-7132-2515-4

ISSN : 0335-5985

Référence électronique

Michael Löwy, « Herold Toussaint, Sociologie d'un Jésuite haittien. Karl Lévêque, éducateur politique », Archives de sciences sociales des religions [En ligne], 172 I octobre-décembre, mis en ligne le 22 juin 2016, consulté le 22 septembre 2020. URL : http://journals.openedition.org/assr/27476 ; DOI : https:// doi.org/10.4000/assr.27476

Ce document a été généré automatiquement le 22 septembre 2020

(C) Archives de sciences sociales des religions 


\section{Herold Toussaint, Sociologie d'un Jésuite haïtien. Karl Lévêque, éducateur politique}

Port-au-Prince, Éditions Presses Nationales d'Haïti, 2014, 291 p.

Michael Löwy

\section{RÉFÉRENCE}

Herold Toussaint, Sociologie d'un Jésuite haïtien. Karl Lévêque, éducateur politique, Port-au-Prince, Éditions Presses Nationales d'Haïti, 2014, 291 p. 
1 Herold Toussaint, Sociologie d'un Jésuite haïtien. Karl Lévêque, éducateur politique, Port-au-Prince, Éditions Presses Nationales d'Haïti, 2014, 291 p.

2 Herold Toussaint est docteur en sociologie à l'EHESS, professeur à l'université d'État d'Haïti, membre correspondant du CéSor et auteur de plusieurs ouvrages de sciences sociales. Son dernier livre est un apport important à la connaissance d'un chapitre ignoré (ou oublié) du catholicisme haïtien : la vie et l'œuvre du penseur jésuite haïtien Karl Lévêque (1937-1986), socialiste chrétien et adversaire intransigeant du clan Duvalier. Ce livre constitue une remarquable biographie intellectuelle, à la fois politique et religieuse.

3 Issu de la bourgeoisie mulâtre haïtienne,

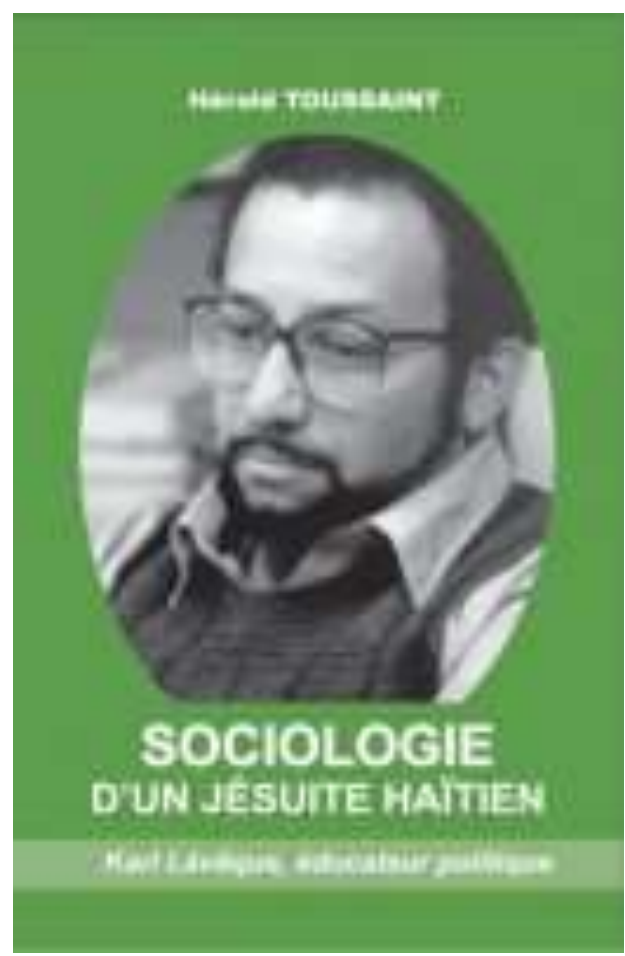
Karl Lévêque part pour le Canada (Québec) en 1960 en vue de faire son noviciat chez les jésuites. Il est empêché de fouler le sol haïtien à cause de l'expulsion des jésuites par le dictateur François Duvalier en 1964.

Il est donc condamné à vivre en exil pratiquement le reste de sa courte vie. De 1964 à 1967, il prépare un doctorat en France sur «La philosophie de la connaissance de Lucien Lévy-Bruhl » et s'intéresse donc à cette ethnologie typiquement évolutionniste et positiviste, qui oppose la « mentalité primitive pré-logique » à la « mentalité évoluée, scientifique » (de l'Occident, bien entendu)... car, comme le suggère Karl Lévêque luimême, Lévy-Bruhl permet de «reconnaître l'influence de la sensibilité dans le processus de connaissance ".

5 Mais à la même époque, l'apprenti jésuite s'intéresse à des idées autrement plus radicales: le personnalisme d'Emmanuel Mounier, la théologie politique de JeanBaptiste Metz et les écrits de Karl Marx. À partir de 1970 son chemin est tracé : Lévêque devient un chrétien socialiste. Dans les années suivantes, il participera aux Congrès du réseau «Chrétiens pour le Socialisme » $(1972,1975,1984)$ et à des Conférences des théologiens de la libération (à Sâo Paulo, en 1980). Dans un essai de 1979 sur l'Église populaire, il s'inspire des écrits de Gustavo Gutierrez, Leonardo Boff, Hugo Assmann et autres théologiens latino-américains pour critiquer la vision traditionaliste de l'Église : «Le grand danger c'est que l'institution trouve en elle-même sa finalité », trahissant ainsi «l'intention de la première Parole qui avait été son fondement, son commencement ».

6 Penseur anti-dogmatique, Karl Lévêque pense que le marxisme doit s'ouvrir aux réalités nouvelles, inédites au temps de Marx, et à des contributions venant d'autres sources, comme la psychanalyse, la phénoménologie, ou la sociologie moderne. Le socialisme dont il rêve serait sans Goulag et sans Big Brother, parce que « la liberté lui est aussi chère que le pain ». 
7 Exilé au Québec, il n'a pas pu exercer son ministère intellectuel et sacerdotal en Haïti. Mais il s'est occupé activement de défendre les droits des réfugiés haïtiens en Amérique du Nord, contre les persécutions et discriminations racistes. Et il n'a pas cessé de lutter, notamment par ses éditoriaux - au nom du Groupe Culturel « Les Flamboyants » - dans la radio communautaire haïtienne du Québec, contre la dictature des Duvalier (père et fils). Dénonçant cette "dictature fasciste » - et ses soutiens aux États-Unis - ainsi que sa mystificatrice et perverse idéologie raciale "noiriste ", il n'hésite pas à envisager une violence révolutionnaire libératrice en Haïti, suivant l'exemple des Sandinistes, qui ont réussi, au Nicaragua, à renverser la dictature de Somoza. Esprit cosmopolite, il s'intéresse de près aux événements en Amérique Centrale et dans les Caraïbes, dénonce la soumission de l'Église de Saint-Domingue à la dictature de Trujillo, se solidarise avec les documents sociaux de l'Église canadienne, et analyse, avec une distance critique, les discours et encycliques de Jean-Paul II. Suite à la chute de Jean-Claude Duvalier, il revient en Haïti en 1986 mais décède peu après d'un accident chirurgical.

L'ouvrage contient aussi une bibliographie et trois intéressants textes inédits de Karl Lévêque, dont un essai sur le duvaliérisme et une discussion du rapport de Jean-Paul II à la théologie de la libération. En conclusion, une postface de Jean-Marie Louis, s.j., doyen de la Faculté des sciences économiques de l'université Notre-Dame d'Haïti. Il manque une chronologie de sa vie, qui aurait facilité la compréhension de son parcours.

9 Jean-Marc Biron s.j., provincial des jésuites du Canada Français et d'Haïti a écrit une amicale préface. Nous apprenons par ce texte que Hérold Toussaint n'a pas connu Karl Lévêque, mais a entretenu avec lui une correspondance pendant plusieurs années. Il est dommage qu'il n'ait pas fait usage de cette correspondance inédite dans son livre... 